\title{
Region-Specific Developmental Specialization of GABA-Glycine Cosynapses in Laminas I-II of the Rat Spinal Dorsal Horn
}

\author{
A. Florence Keller, ${ }^{1}$ Jeffrey A. M. Coull, ${ }^{2,3}$ Nadège Chéry, ${ }^{2}$ Pierrick Poisbeau, ${ }^{1}$ and Yves De Koninck ${ }^{2,3}$ \\ ${ }^{1}$ Laboratoire de Neurophysiologie Cellulaire et Intégrée, Centre National de la Recherche Scientifique Unité Mixte de \\ Recherche 7519, Université Louis Pasteur, 67084 Strasbourg cedex, France, 2Department of Pharmacology and \\ Therapeutics, McGill University, Montréal, Québec, Canada H3G 1Y6, and ${ }^{3 N e u r o b i o l o g i e ~ C e l l u l a i r e, ~ C e n t r e ~ d e ~}$ \\ Recherche Université Laval Robert-Giffard, Beauport, Québec, Canada G1J 2G3
}

The spinal dorsal horn is the first level of the CNS in which nociceptive input from sensory afferents is integrated and transmitted. Although inhibitory control in this region has a crucial impact on pain transmission, the respective contribution of GABA and glycine to this inhibition remains elusive. We have previously documented co-release of GABA and glycine at the same inhibitory synapse in spinal laminas I-II of adult rats [older than postnatal day 30 (P30)]. However, despite this co-release, individual miniature inhibitory postsynaptic currents (mIPSCs) were mediated by either glycine receptors (GlyR) or $\mathrm{GABA}_{\mathrm{A}}$ receptors $\left(G A B A_{A} R\right)$, yet never by the two together. In contrast, recent studies of ventral horn immature inhibitory synapses ( $\leq$ P21) reported individual mIPSCs that were mediated by both $\mathrm{GABA}_{A}$ Rs and GlyRs. This raises the question of whether mixed mIPSCs are present in immature lamina I-II neurons yet are lost through a maturation-dependent synaptic specialization. To test this, we recorded mIPSCs using patch-clamp techniques in

Laminas I and II of the spinal dorsal horn are key areas in the CNS in which pain-related, or nociceptive information that is carried by sensory afferents is integrated and relayed to higher brain structures. Thus, the control of excitability of lamina I-II neurons has a major impact on pain perception. Glycine and GABA are the main transmitters responsible for inhibitory control in this region and therefore play a crucial role in nociception. For example, blocking $\mathrm{GABA}_{\mathrm{A}}$ or glycine receptors $\left(\mathrm{GABA}_{\mathrm{A}} \mathrm{Rs}\right.$ or GlyRs, respectively) in the superficial dorsal horn can cause conditions of hyperexcitability characteristic of neuropathic pain syndromes (Yaksh, 1989; Sherman and Loomis, 1996; Sorkin and Puig, 1996). Yet, the exact respective contributions of GABA and glycine to inhibitory control in this area remain largely unknown.

\footnotetext{
Received Jan. 19, 2001; revised July 5, 2001; accepted July 11, 2001.

This work was supported by Canadian Institutes of Health Research (CIHR) Grant MT12942, a grant from the Natural Science and Engineering Research Council of Canada, a team grant from the Fonds pour la Formation de Chercheurs et l'Aide à la Recherche du Québec, the Centre National de la Recherche Scientifique-Université Louis Pasteur, and by the Institut UPSA de la douleur. J.A.M.C. is the recipient of a Canadian Pain Society-Janssen-Ortho Inc.-CIHR doctoral award. A.F.K. is a fellow of the Centre de Coopération Inter-Universitaire FrancoQuébécois. Y.D.K. is a scholar of the Fonds de la Recherché en Santé du Québec (FRSQ). We thank A. Constantin for expert technical assistance and Hoffman-La Roche for the generous donation of benzodiazepines.

A.F.K. and J.A.M.C. contributed equally to this work.

Correspondence should be addressed to Dr. Yves De Koninck, Neurobiologie Cellulaire, Centre de Recherche Université Laval Robert-Giffard, 2601, Chemin de la Canardière, Beauport, Québec, Canada G1J 2G3. E-mail: Yves.DeKoninck@ crulrg.ulaval.ca.

Copyright () 2001 Society for Neuroscience $\quad 0270-6474 / 01 / 217871-10 \$ 15.00 / 0$
}

lamina I-II neurons in spinal slices taken at different stages of development. We found that, in neurons younger than P23, both GlyR-only and GABA $A_{A}$-only mIPSCs could be recorded, in addition to mixed $\mathrm{GABA}_{\mathrm{A}} \mathrm{R}-\mathrm{GlyR}$ mIPSCs. With maturation however, both lamina I-II neurons gradually discontinued exhibiting mixed mIPSCs, although with differing patterns of specialization. Yet, at all developmental stages, benzodiazepine administration could unmask mixed mIPSCs. Together, these findings indicate that, although GABA and glycine are continually co-released throughout development, junctional codetection ceases by adulthood. This indicates an age-dependent postsynaptic tuning of inhibitory synapses that occurs in a region-specific manner.

Key words: pain; nociception; development; plasticity; inhibition; cotransmission; mIPSCs; GABA ${ }_{A}$; quantal release; substantia gelatinosa; marginal layer; silent synapse
Immunocytochemical studies have provided substantial evidence in favor of a colocalization of GABA and glycine as well as their respective receptors in the dorsal horn (Todd et al., 1996). For example, the vesicular inhibitory amino acid transporter (VIAAT), which is known to carry both glycine and GABA (for review, see Gasnier, 2000), has been shown in almost every inhibitory bouton in laminas I-III (Chaudhry et al., 1998; Dumoulin et al., 1999). Not surprisingly, virtually all glycinergic neurons in this region are also immunoreactive for GABA (Todd and Sullivan, 1990; Mitchell et al., 1993). Recent reports have demonstrated the co-release of GABA and glycine from individual vesicles at some synapses (Jonas et al., 1998; Chéry and De Koninck, 1999b; O'Brien and Berger, 1999). More precisely, the studies by Jonas et al. (1998) and O'Brien and Berger (1999) have shown that GABA and glycine can be co-released from interneurons in the immature ventral horn to activate both postsynaptic $\mathrm{GABA}_{\mathrm{A}} \mathrm{Rs}$ and GlyRs simultaneously. In contrast, although we have also demonstrated recently the co-release of GABA and glycine in adult laminas I-II (Chéry and De Koninck, 1999b), our results indicated that quantal postsynaptic currents were either GlyR- or GABA $\mathrm{A}$-mediated, never both, in these adult cells. Together, these findings could suggest a specialization of inhibitory synapses with maturation.

We investigated this possibility in the present study using whole-cell patch-clamp techniques on transverse and parasagittal slices of spinal cord to record and analyze action-potential independent miniature inhibitory postsynaptic currents (mIPSCs), 
which are thought to reflect the release of single vesicles of transmitter. We found that in immature rats [postnatal day 8 (P8) to P23], most neurons in laminas I-II not only exhibited both GABA $_{\mathrm{A}} \mathrm{R}$ - and GlyR-mediated mIPSCs but also mixed GABA $_{\mathrm{A}} \mathrm{R}-$ GlyR mIPSCs. These mixed mIPSCs decreased in proportion with age, disappearing by $\mathrm{P} 23$, at which time neurons could be differentiated as displaying either GlyR-only or $\mathrm{GABA}_{\mathrm{A}}$ R-only mIPSCs, but with lamina-specific patterns of specialization. Additionally, both $\mathrm{GABA}_{\mathrm{A}} \mathrm{R}$ - and GlyR-mediated mIPSCs displayed a quickening of decay kinetics with age, especially in the case of GABA $\mathrm{A}_{\mathrm{A}}$. This allowed for a region-specific tuning of inhibitory charge carried during quantal events via an age-dependent specialization.

Preliminary results of this study have been published previously (Coull et al., 2000).

\section{MATERIALS AND METHODS}

In this study we used slices from immature (P8-P23) or adult male (>P23) Wistar or Sprague Dawley rats. These slices were cut in either the parasagittal or transverse plane after removal of spinal cord by laminectomy or hydraulic extrusion. All dissections were performed in the presence of ice-cold $\left(\leq 4^{\circ} \mathrm{C}\right)$ saccharose-artificial CSF (S-ACSF) containing (in mM): 248 saccharose, 11 glucose, $2 \mathrm{NaHCO}_{3}, 2 \mathrm{KCl}, 1.25$ $\mathrm{KH}_{2} \mathrm{PO}_{4}, 2 \mathrm{CaCl}_{2}, 2 \mathrm{MgSO}_{4}, \mathrm{pH} 7.35 \pm 0.05$. S-ACSF was bubbled continuously with $95 \% \mathrm{O}_{2} / 5 \% \mathrm{CO}_{2}$.

Laminectomy. Rats were deeply anesthetized with a mixture of ketamine $(75 \mathrm{mg} / \mathrm{kg}$, i.p.) and xylazine $(5 \mathrm{mg} / \mathrm{kg}$, i.p.). To limit hemorrhage and excitotoxicity during the dissection procedure, we systematically performed bilateral injections of xylocaine-adrenaline $(2 \%)$ in the spine muscles of the thoracolumbar spinal cord segments. Vertebral laminectomy was then performed, followed by dorsal and ventral root transection and in situ meninges removal.

Hydraulic extrusion. We previously described the protocol for hydraulic extrusion of rat spinal cords (Chéry et al., 2000). Briefly, rats were anesthetized with sodium pentobarbital $(30 \mathrm{mg} / \mathrm{kg})$; then, adult rats were perfused intracardially with ice-cold S-ACSF, whereas immature rats were immersed in ice-cold water for 4-5 min. After either perfusion or immersion, both groups of rats were rapidly decapitated. The sacral vertebral column was transected, and a syringe was used to inject S-ACSF into the foramen, thus ejecting the spinal cord.

Slice preparation. Cervical and lumbar segments $(0.5-2 \mathrm{~cm}$ long) were isolated and glued with cyanoacrylate cement, either lateral side down (allowing for parasagittal slicing) or vertically, supported by an agarose block (allowing for transverse slicing), to the platform of a Vibratome chamber filled with oxygenated ice-cold S-ACSF. Slices $(300-400 \mu \mathrm{m}$ thick) were cut, incubated in S-ACSF at room temperature $\left(23-28^{\circ} \mathrm{C}\right)$ for $30 \mathrm{~min}$, and transferred to normal ACSF for at least $1 \mathrm{hr}$ before electrophysiological recordings. Finally, slices were transferred to a recording chamber under a Zeiss Axioscope that was equipped with infrared differential interference contrast (IR-DIC) and water immersion objectives for visualization of neurons in thick live tissue. The slices were continuously perfused with oxygenated normal ACSF in which $125 \mathrm{~mm}$ $\mathrm{NaCl}$ was substituted for saccharose. To increase the frequency of occurrence of mIPSCs, $100 \mu \mathrm{M}$ ruthenium red (Sigma, St. Louis, MO) was applied to the bath chamber for some slices $(n=25)$. Ruthenium red is a polyvalent cation that blocks voltage-dependent calcium channels and enhances mIPSC frequency via a $\mathrm{Ca}^{2+}$-independent mechanism (Sciancalepore et al., 1998; Trudeau et al., 1998; Hoffman and Lupica, 2000).

Electrophysiological recordings, data acquisition, and analysis. All recordings were made at room temperature. For voltage-clamp experiments, patch pipettes were obtained by pulling borosilicate glass capillaries with inner filament using a horizontal laser puller (P-2000; Sutter Instruments, Novato, CA) or a two-stage vertical puller (PP-83; Narishige, Tokyo, Japan). The pipettes were filled with a solution containing (in $\mathrm{mm}$ ): $130 \mathrm{CsCl}, 2 \mathrm{MgCl}_{2}, 10 \mathrm{HEPES}, \mathrm{pH} 7.3$, adjusted with $\mathrm{CsOH}$. Approximately $60 \%$ of the recordings were made with $0.4 \mathrm{mM} \mathrm{GTP}$ and 2 mM ATP (Sigma) added to the intracellular solution. Because no differences in mIPSC characteristics were observed among the two conditions, all data were pooled. Whole-cell patch-clamp recordings were obtained using an Axopatch 200B amplifier (Axon Instruments, Foster City, CA) with $>80 \%$ series resistance compensation.
Recordings were low-pass filtered $(5-10 \mathrm{kHz})$, digitized, and stored on videotape. Off-line, recordings were filtered at $2 \mathrm{kHz}$ and digitized at $4-10 \mathrm{kHz}$ on an Intel Pentium-based computer. Data were acquired and analyzed using the Strathclyde electrophysiology software CDR (courtesy of Dr. J. Dempster, University of Strathclyde, Glasgow, UK) and analysis software designed by Y.D.K.

Detection of individual mIPSCs was performed using a software trigger previously described in detail (Chéry and De Koninck, 1999b; Poisbeau et al., 1999). More than $95 \%$ of events that satisfied the trigger criteria were detected, even during compound mIPSCs. For each experiment, all detected events were examined individually, and any noise that spuriously met trigger specification was rejected.

Statistical analysis and curve fitting. Peak amplitudes, rise times, and decay time constants were calculated for each of several hundreds of mIPSCs per cell, using an automated algorithm (De Koninck and Mody, 1994, 1996). Averages of several hundred mIPSCs were also superimposed for comparison. Decay time constants were fitted using a leastsquare method that was based on a simplex algorithm as previously described (De Koninck and Mody, 1994). The goodness of fit was evaluated on the basis of fitting subsets of points drawn from the whole set of data points as well as from evaluation of the reduced $\chi^{2}: \chi_{v}{ }^{2}=\chi^{2} / v$, where the factor $v=N-n$ is the number of degrees of freedom left after fitting $N$ data points to the $n$ parameters. The necessity to introduce additional exponential components to the fits was judged first on the basis of visual inspection of the fitted curves superimposed onto the data. When the merit of additional components was not obvious, an $F$ test was used to assess how the additional component improved the value of the reduced $\chi^{2}: F_{X}=\Delta \chi^{2} / \chi_{v}{ }^{2}\left(\mathrm{df}_{1}=1\right.$ and $\left.\mathrm{df}_{2}=v\right)$. The critical value for the merit of additional components was set at a low level $(p<0.01)$ to favor parsimony of the fitted function. When focusing on comparisons of the late component of mIPSCs, fits were started at a fixed interval after the peak of the event to allow for nonequivocal monoexponential fits that provide an easier and fairer reference when dealing with nonaveraged, individual traces (De Koninck and Mody, 1994; Chéry and De Koninck, 1999b). This also avoided contamination of the values of decay time constants with variable weighting factors. Student's $t$ tests were used to analyze the differences between parameters of the GABA $\mathrm{A}$ - and GlyRmediated IPSCs. Cumulative probability distributions were compared using the Kolmogorov-Smirnov test. $\chi^{2}$ tests for contingency tables were performed to determine the correlation between the laminar location of the cells and the presence of $\mathrm{GABA}_{\mathrm{A}} \mathrm{R}$ - and GlyR-mediated mIPSCs. The critical value for statistical significance was set at $p<0.05$. All data are expressed as mean \pm SEM, unless otherwise indicated.

Drug application. Slices were continually perfused with oxygenated ACSF containing tetrodotoxin $(0.5 \mu \mathrm{M}$; Sigma) and either kynurenic acid (2 mM; Fluka, Neu-Ulm, Germany) or 6-cyano-7-nitroquinoxaline-2,3dione (10 $\mu \mathrm{M}$; Tocris Cookson, Ballwin, MO) and D2-amino-5phosphonovaleric acid ( $40 \mu \mathrm{M}$; Tocris Cookson). For selective blockade of glycine receptors, strychnine hydrochloride $(200 \mathrm{nM}-1 \mu \mathrm{M}$; Research Biochemicals, Natick, MA) was used. For selective blockade of GABA receptors, bicuculline methiodide $(10 \mu \mathrm{M}$; Research Biochemicals) or SR-95531 (Gabazine; $3 \mu \mathrm{M}$; Research Biochemicals) was used. All drugs were prepared as $1000 \times$ concentrated frozen stock solution aliquots. Diazepam (Sigma) was diluted in $96 \%$ ethanol, whereas all other drugs were prepared in distilled water.

\section{RESULTS}

Whole-cell voltage-clamp recordings of mIPSCs from 68 adult $(>$ P30) and 78 immature (P8-P23) lamina I and II neurons are included in this report. Neurons were selected if they could be recorded from for a sufficient duration $(>15 \mathrm{~min})$ with stable access resistance throughout (7-20 M $\Omega$ ). Spinal slices were obtained from either lumbar or cervical spinal enlargements. Consistent with our previous reports, no differences were observed in recordings between the two regions, in terms of mIPSC frequency or kinetics (Chéry and De Koninck, 1999b).

Lamina II neurons were accessed using either a parasagittal or a transverse spinal slice preparation. Optimal identification of lamina I neurons required the use of a parasagittal slice. As previously described (Chéry et al., 2000), we defined lamina I neurons as those found within $30 \mu \mathrm{m}$ of the outlying dorsal white matter in the parasagittal configuration. No significant differences 


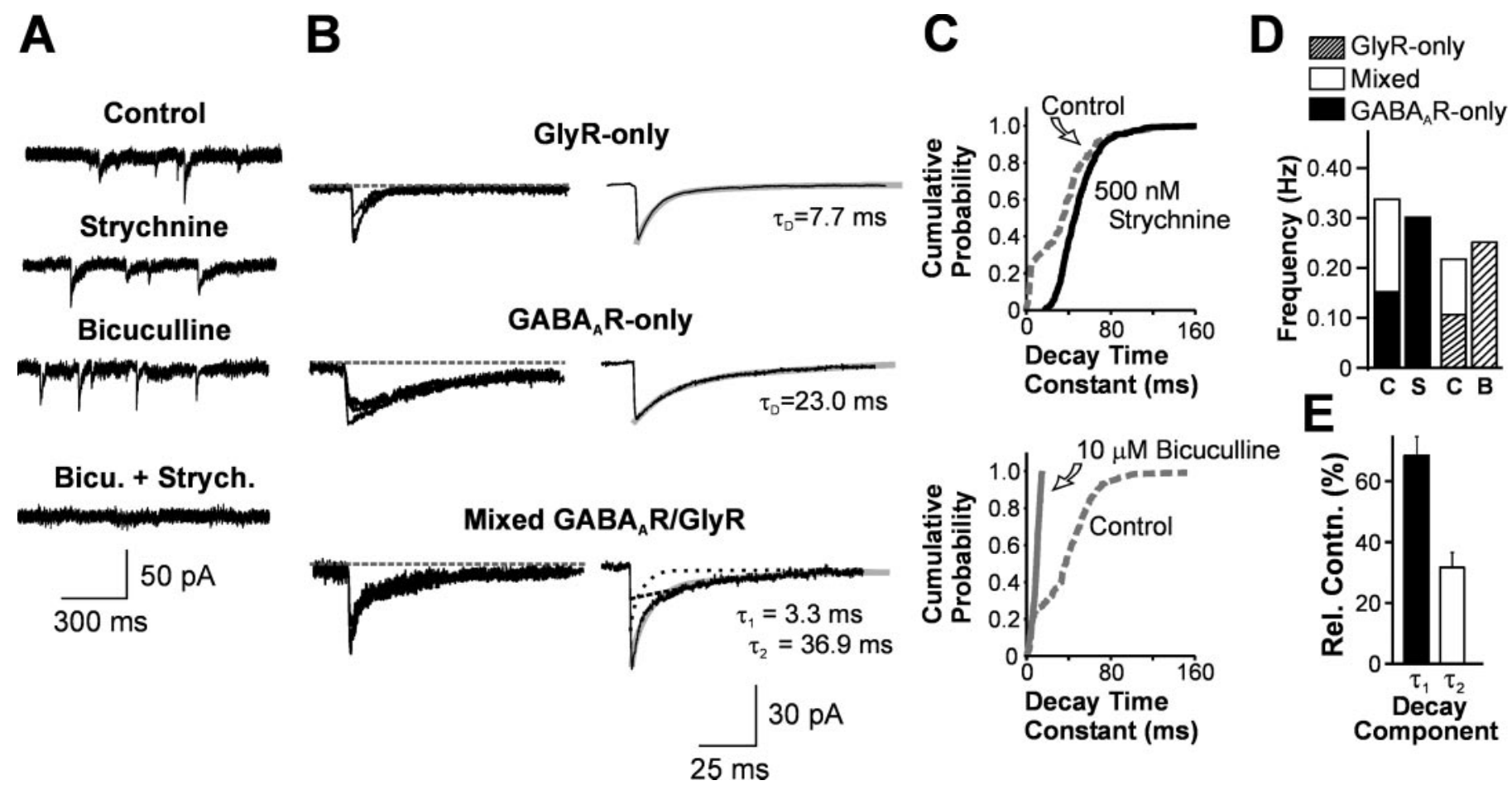

Figure 1. Three distinct types of mIPSCs could be recorded from immature (P8-P23) neurons in the superficial dorsal horn. A, Raw traces of spontaneously occurring mIPSCs in a P14 lamina I neuron in control conditions, in the presence of either strychnine (500 nM) or bicuculline (10 $\mu \mathrm{M})$, as well as in the presence of both antagonists. Although strychnine or bicuculline alone only blocked a subpopulation of mIPSCs, no events were left in the concurrent presence of both antagonists. Note how the events remaining in the presence of strychnine have a distinctly slower decay time course than those remaining in the presence of bicuculline. Holding membrane potential $\left(V_{\mathrm{H}}\right)$ was $-60 \mathrm{mV}$. $B$, The mIPSCs could be separated into three distinct categories on the basis of their decay kinetics: events with a rapid monoexponential decay phase, which persisted in the presence of bicuculline, thus apparently being mediated by GlyRs (GlyR-only); events with a slow monoexponential decay phase, which persisted in strychnine, thus apparently being mediated by $\mathrm{GABA}_{\mathrm{A}} \mathrm{Rs}\left(G A B A_{A} R\right.$-only); and events with clear double decay kinetics that were absent in the presence of either strychnine or bicuculline, and therefore involving activation of both $\mathrm{GABA}_{\mathrm{A}} \mathrm{Rs}$ and GlyRs (mixed GABA $A_{A} R-G l y R$ mIPSCs). Traces on the left are superimposed individual events $(n=3$, each). Traces to the right are averages of 100 consecutive events. $C$, Cumulative probability plots of decay time constants of mIPSCs recorded from two P8 neurons. The plots were constructed by forcing monoexponential fits to all individual mIPSCs recorded under control conditions (dashed line) and then in the presence of either $500 \mathrm{nM}$ strychnine (solid black line) in one neuron (top) or $10 \mu \mathrm{M}$ bicuculline (solid gray line) in another neuron (bottom). A clear bimodal distribution of decay times is observable in control conditions, whereas strychnine and bicuculline selectively abolish the early or late mode, respectively. $D$, The sum of the frequencies of kinetically isolated monoexponential mIPSCs and biexponential mI PSCs was similar to the frequency of that same monoexponential mIPSC when isolated pharmacologically. For illustration, individual examples are provided. In an immature lamina II neuron (P14), in control conditions ( $C$ ), kinetically isolated slow monoexponentially decaying mIPSCs (solid black bar) occurred at a frequency of $0.15 \mathrm{~Hz}$, whereas that for mixed mIPSCs (solid white bar) was $0.18 \mathrm{~Hz}$. The sum of these frequencies $(0.34 \mathrm{~Hz})$ was comparable to that of GABA $\mathrm{A}_{\mathrm{A}} \mathrm{R}$-only mIPSCs recorded in the presence of strychnine $(S ; 0.30 \mathrm{~Hz})$. A similar example is provided using bicuculline to isolate GlyR events $(C$ vs $B$ ). See Results for further details, population data, and statistical analysis. $E$, In mixed GABA $\mathrm{A}-\mathrm{GlyR}$ mIPSCs, the mean relative contribution (Rel. Contn.) of the fast $\left(\tau_{1}\right)$ and the slow decay component $\left(\tau_{2}\right)$ was $65 \pm 10 \%$ and $35 \pm 6 \%$, respectively $(n=10)$.

were observed in recordings obtained using the different slice preparations, and thus data were pooled.

In some cases, we bath-applied $100 \mu \mathrm{M}$ ruthenium red, a polyvalent cation that blocks voltage-dependent calcium channels, to increase mIPSC frequency $(n=25)$. We observed no significant differences in recordings from cells in the absence or presence of ruthenium red, in terms of decay time constant $\left(\mathrm{GABA}_{\mathrm{A}} \mathrm{R}\right.$ only, $23.5 \pm 11.2$ vs $27.5 \pm 1.8 \mathrm{msec}$; GlyR only, $9.7 \pm 1.0$ vs $10.0 \pm 1.3$ $\mathrm{msec})$ or $10-90 \%$ rise time $\left(\mathrm{GABA}_{\mathrm{A}} \mathrm{R}\right.$ only, $1.1 \pm 0.3$ vs $1.0 \pm 0.1$ msec; GlyR only, $1.1 \pm 0.2$ vs $0.9 \pm 0.2 \mathrm{msec}$; tested in 16 cells all taken at P14).

\section{GlyR- and GABA $\mathbf{A}$-mediated mIPSCs}

Before P23, all neurons in lamina I $(100 \% ; n=12)$ and the majority of neurons in lamina II $(72 \% ; n=47)$ exhibited quantal events mediated by GlyRs and by $\mathrm{GABA}_{\mathrm{A}} \mathrm{Rs}$, as well as by both types of receptors concurrently (see below). The remaining lamina II neurons displayed events mediated either solely by glycine receptors (termed hereafter GlyR-only mIPSCs; $n=3$ or $4 \%$ of cells) or by $\mathrm{GABA}_{\mathrm{A}}$ receptors (termed hereafter $\mathrm{GABA}_{\mathrm{A}} \mathrm{R}$-only mIPSCs; $n=16$ or $24 \%$ of cells). In neurons displaying both GlyR- and $\mathrm{GABA}_{\mathrm{A}} \mathrm{R}$-mediated events, the simultaneous presence of bicuculline $(10 \mu \mathrm{M})$ and strychnine $(500 \mathrm{nM})$ was required to completely and reversibly abolish miniature events (Fig. 1A). Kinetic analysis revealed that the decay phase of the bicucullinesensitive $\mathrm{GABA}_{\mathrm{A}} \mathrm{R}$-only mIPSCs was significantly slower than that of strychnine-sensitive GlyR-only mIPSCs (Fig. 1B). This is further highlighted in Figure $1 C$, which shows the cumulative probability distribution of mIPSC decay time constants in two neurons. In control conditions, a clear bimodal distribution of decay time constants indicated two kinetically distinct populations of mIPSCs within this cell. Each of the two peaks represented by this bimodal distribution could be selectively abolished by the administration of bicuculline or strychnine, respectively. Generally, pharmacologically isolated $\mathrm{GABA}_{\mathrm{A}} \mathrm{R}$ - and GlyR-only mIPSCs possessed decay phases that could be appropriately fitted by a monoexponential function (Fig. $1 B$ ). 


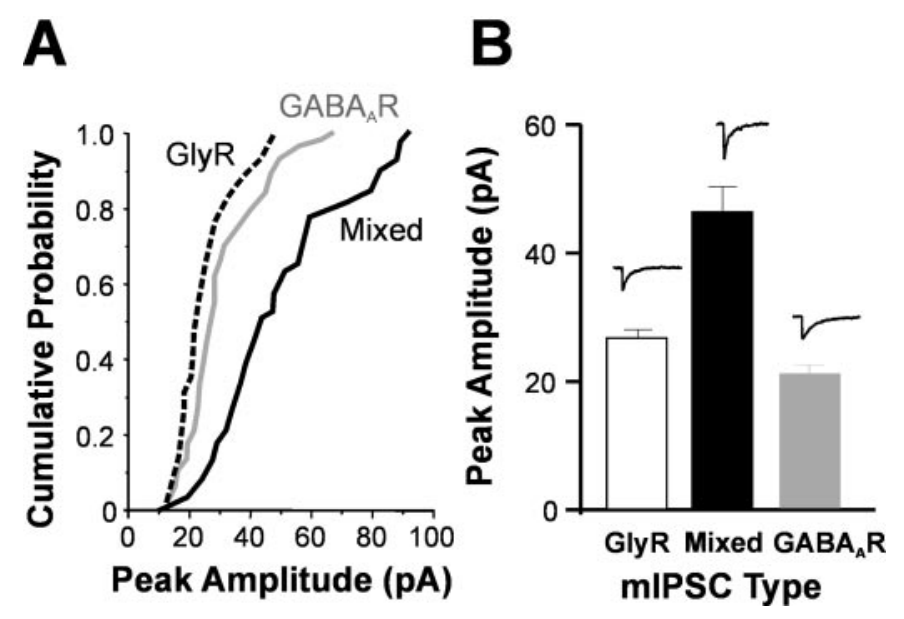

Figure 2. Mixed $\mathrm{GABA}_{\mathrm{A}} \mathrm{R}-\mathrm{GlyR}$ mIPSCs have significantly greater peak amplitudes than either GABA ${ }_{\mathrm{A}} \mathrm{R}$-only or GlyR-only mIPSCs. $A$, Cumulative probability plot highlighting the difference in peak amplitude distribution between mixed GABA ${ }_{\mathrm{A}} \mathrm{R}-\mathrm{GlyR}$ mIPSCs (solid black line), GlyR-only (dashed line), and $\mathrm{GABA}_{\mathrm{A}} \mathrm{R}$-only mIPSCs (solid gray line) recorded from the same lamina II neuron (age P17; each neuron is used as its own control to avoid confounding effects of cell-cell variation in mean mIPSC amplitude; the same analysis was replicated in $n=10$ neurons and yielded similar results). $B$, From the same neuron described in $A$, the mean peak amplitude of mixed $\mathrm{GABA}_{\mathrm{A}} \mathrm{R}-\mathrm{GlyR}$ mIPSCs was $47 \pm 4 \mathrm{pA}$, representing an amplitude $\sim 113 \%$ greater than that of GABA $_{\mathrm{A}}$ R-only mIPSCs $(22 \pm 2 \mathrm{pA} ; p<0.05)$ and $\sim 74 \%$ greater than the mean peak amplitude of GlyR-only mIPSCs $(27 \pm 2 \mathrm{pA} ; p<0.05)$. The insets above each bar are representative traces of mIPSCs from each category.

\section{Mixed GABA $A$ R-GlyR-mediated mIPSCs}

In the absence of inhibitory amino acid receptor antagonists, a population of individual mIPSCs with a prominent dual component could be observed in neurons in both laminas I and II. Mixed mIPSCs illustrated at the bottom of Figure $1 B$ represented as many as $27 \%$ of the total number of mIPSCs displayed by an immature neuron. This proportion of dual component mIPSCs was found further to be not significantly different when superficial neurons were recorded using $\mathrm{Cs}_{2} \mathrm{SO}_{4}$-containing electrodes $\left(\mathrm{E}_{\mathrm{C} 1}\right.$ $\sim-60 \mathrm{mV})$ at a holding potential of $0 \mathrm{mV}(n=9$, data not shown). The relative contribution of the fast decay component to these mIPSCs $\left(\tau_{1}\right)$ was consistently $66 \pm 10 \%$, compared with that of the slow decay component $\left(\tau_{2}\right)$, which was $33 \pm 6 \%(n=$ 10) (Fig. 1E).

Importantly, biexponential mIPSCs were absent in the presence of either bicuculline or strychnine, and when fitted with double exponential decay functions yielded components that had kinetics comparable to that of their pharmacologically isolated counterparts $\left(\mathrm{GABA}_{\mathrm{A}} \mathrm{R}\right.$-only and GlyR-only mIPSCs). In addition, the frequency of pharmacologically isolated monoexponential mIPSCs was found to be similar to the sum of the frequencies of the monoexponential mIPSCs and biexponential mIPSCs when isolated kinetically in neurons younger than P23 (Fig. 1D). That is, the frequency of GlyR-only mIPSCs in the presence of bicuculline $(0.43 \pm 0.1 \mathrm{~Hz})$ was not significantly different from the sum of the frequencies of kinetically isolated fast monoexponentially decaying mIPSCs and dual component mIPSCs $(0.42 \pm$ $0.09 \mathrm{~Hz}, n=8, p>0.05)$. Similarly, after strychnine application, the frequency of pharmacologically isolated $\mathrm{GABA}_{\mathrm{A}} \mathrm{R}$-only mIPSCs $(0.33 \pm 0.09 \mathrm{~Hz})$ was equivalent to the sum of the mean frequencies of kinetically isolated slow monoexponentially decay-
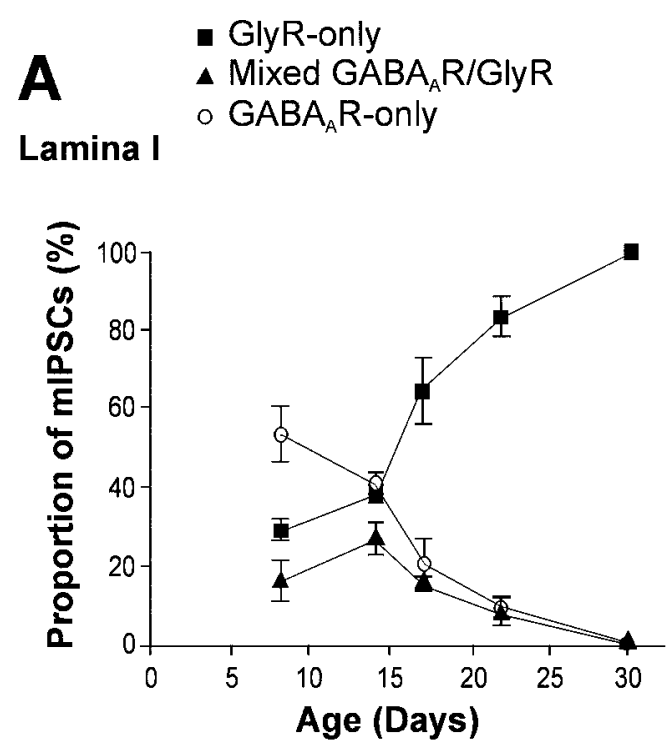

B

\section{Lamina II}

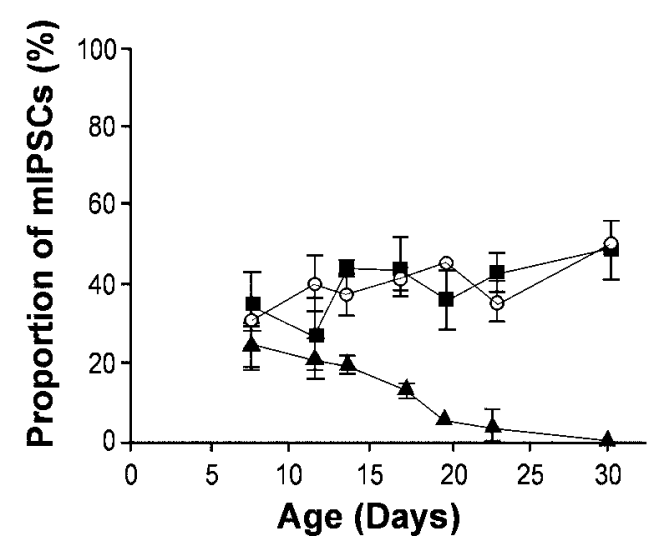

Figure 3. The proportion of mixed $\mathrm{GABA}_{\mathrm{A}} \mathrm{R}-\mathrm{GlyR}$ mIPSCs decreased with maturation in both lamina I and II neurons. $A$, In lamina I neurons, mixed $\mathrm{GABA}_{\mathrm{A}} \mathrm{R}-\mathrm{GlyR}$ mIPSCs (solid triangles) virtually disappeared along with $\mathrm{GABA}_{\mathrm{A}} \mathrm{R}$-only mIPSCs (open circles) by $\sim \mathrm{P} 23$, after which, only GlyR-only mIPSCs (solid squares) could be detected. $B$, Lamina II neurons also discontinued to display mixed GABA $\mathrm{A}_{\mathrm{A}}$ - GlyR mIPSCs by $\sim$ P23. However, in contrast to lamina I neurons, mIPSCs recorded in adult lamina II were evenly divided into $\mathrm{GABA}_{\mathrm{A}} \mathrm{R}$-only and GlyR-only. All data points, $3 \leq n \leq 6$.

ing mIPSCs and dual component mIPSCs $(0.36 \pm 0.1, n=17$, $p>0.05)$. These results are consistent with the interpretation that, in these cells, mIPSCs with a prominent biexponential decay possess both a $\mathrm{GABA}_{\mathrm{A}} \mathrm{R}$ and a GlyR component, and can be reduced to a monoexponential mIPSC of either variety simply by blocking the other component. Consistent with this observation is also the fact that dual component mIPSCs had peak amplitudes that were on average twice that of GlyR-only mIPSCs or $\mathrm{GABA}_{\mathrm{A}}$ R-only mIPSCs (confirmed in all of 51 neurons tested; ages P8-P22) (Fig. 2). Together, all of these results suggest the synchronous coactivation of synaptic $\mathrm{GABA}_{\mathrm{A}} \mathrm{Rs}$ and GlyRs during a subgroup of quantal inhibitory events in lamina I-II neurons. These events will henceforth be referred to as mixed $\mathrm{GABA}_{\mathrm{A}} \mathrm{R}-\mathrm{GlyR}$ mIPSCs. 


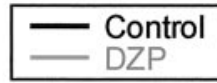

A GlyR-only
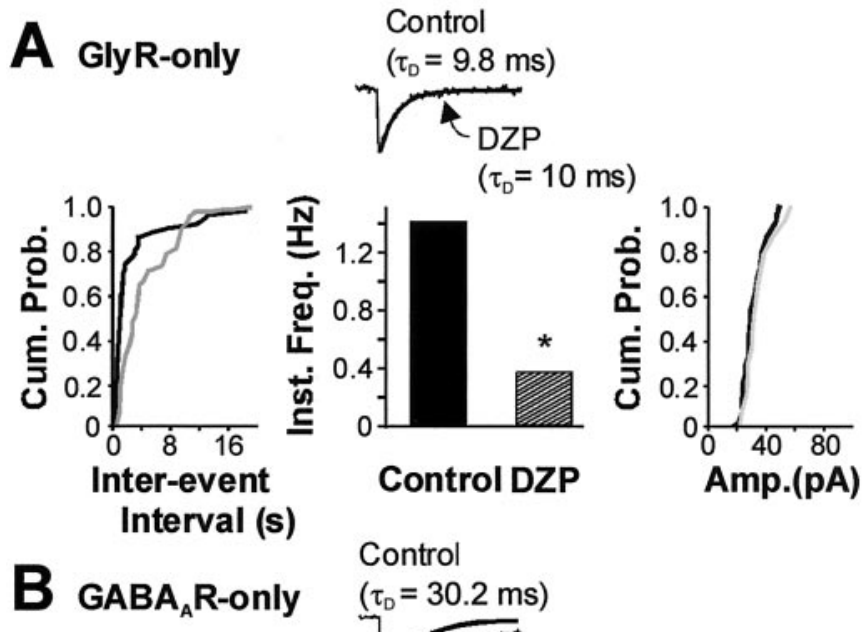

\section{Control}

$\left(\tau_{\mathrm{D}}=30.2 \mathrm{~ms}\right)$

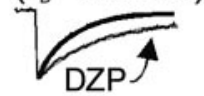

$\left(\tau_{\mathrm{D}}=58.7 \mathrm{~ms}\right)$
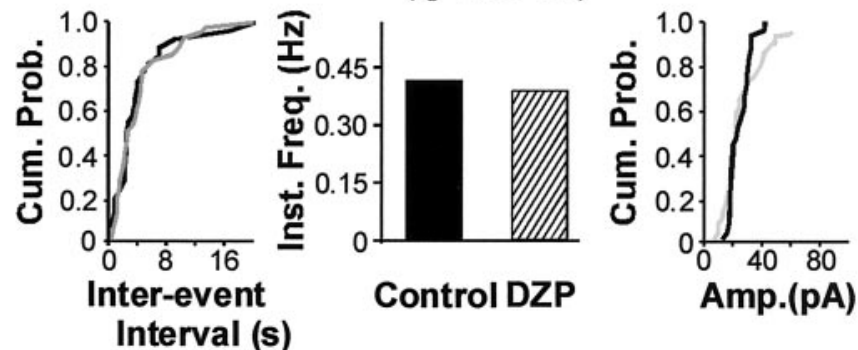

C Mixed

Control

$\left(\tau_{1}=8.3 \mathrm{~ms}, \tau_{2}=31.1 \mathrm{~ms}\right)$

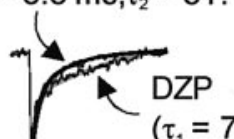

$\left(\tau_{1}=7.9 \mathrm{~ms}, \tau_{2}=67.4 \mathrm{~ms}\right)$
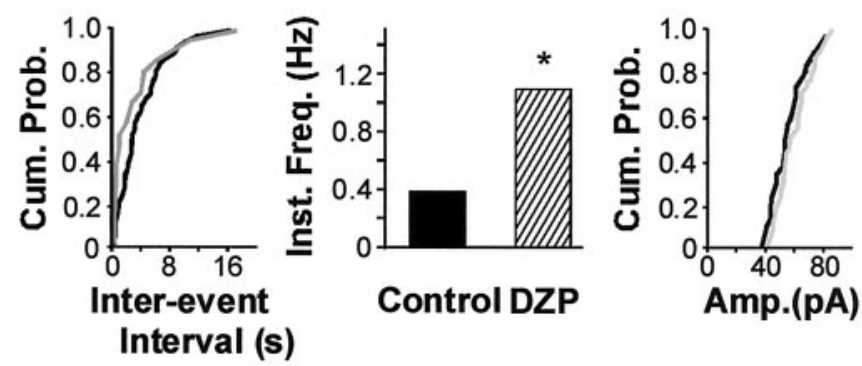

Figure 4. Addition of a benzodiazepine revealed that co-release still occurred during GlyR-only mIPSCs. An example from a P13 lamina II neuron is shown; measurements were made under steady-state conditions. $A$, Neither the cumulative distribution of peak amplitudes (right), nor the decay time constant of the group of mIPSCs characterized by a rapid monoexponential decay phase (GlyR-only) was changed significantly with the administration of diazepam $(D Z P ; 1 \mu \mathrm{M})$ (center, inset). Interevent interval (left) was, however, prolonged with DZP, yielding a significant decrease in its reciprocal parameter, instantaneous frequency (center, control, $1.4 \mathrm{~Hz}$, vs DZP, $0.37 \mathrm{~Hz} ; p<0.05$ ). $B, C$, In contrast, the groups of mIPSCs with a slower monoexponential decay phase $\left(G A B A_{A} R\right.$-only) and with a dual exponential decay phase (mixed GABA $A_{A} R-G l y R$ mIPSCs) were prolonged in the presence of DZP (respective center insets). Mean decay of $\mathrm{GABA}_{\mathrm{A}} \mathrm{R}$-only mIPSCs was prolonged from 30.2 to $58.7 \mathrm{msec}$ $(B$, inset $)$. Mixed GABA $\mathrm{R}-\mathrm{GlyR}$ mIPSCs only exhibited an increase in $\tau_{2}$, from 31.1 to $67.4 \mathrm{msec}$, whereas $\tau_{1}$ remained stable $(C$, inset $)$. Note that the mean peak amplitude of $\mathrm{GABA}_{\mathrm{A}} \mathrm{R}$-only $(B$, right $)$ and mixed

\section{Age-dependent disappearance of mixed GABA $_{\mathrm{A}}$ R-GlyR mIPSCs}

We observed a disappearance of mixed GABA ${ }_{A} \mathrm{R}-$ GlyR mIPSCs with development. In lamina I (Fig. $3 A$ ), the proportion of these events peaked at P14 (27\%), and then decreased in a linear fashion, becoming virtually undetectable by approximately $\mathrm{P} 23$. Interestingly, and similar to the mixed mIPSCs, $\mathrm{GABA}_{\mathrm{A}} \mathrm{R}$-only mIPSCs were also gradually lost in lamina I with maturation and were virtually absent beyond P23. Thus, consistent with our previous results (Chéry and De Koninck, 1999b), adult lamina I neurons only expressed GlyR-only mIPSCs $(n=39)$.

A similar trend in the disappearance of mixed $\mathrm{GABA}_{\mathrm{A}} \mathrm{R}-$ GlyR mIPSCs was also observed in lamina II neurons (Fig. $3 B$ ). Again, mixed events were excluded by approximately P23. In contrast to lamina I, however, the synaptic events recorded in adult lamina II neurons were evenly divided into $\mathrm{GABA}_{\mathrm{A}} \mathrm{R}$ only mIPSCs and GlyR-only mIPSCs (52 vs $48 \%$, respectively; $n=33)$.

Additionally, the decrease in the proportion of mixed mIPSCs in lamina I and II neurons was not correlated with a significant change in the relative contribution of the fast decaying component to the peak amplitude of mixed events (P8-P15, $\mathrm{A}_{\mathrm{GlyR}} /$ $\mathrm{A}_{\text {Total }}=58.5 \pm 9.6, n=36 ; \mathrm{P} 20-\mathrm{P} 22, \mathrm{~A}_{\mathrm{GlyR}} / \mathrm{A}_{\text {Total }}=69.7 \pm 9.6$, $n=5 ; p>0.05)$.

\section{Diazepam revealed that co-release still occurred during GlyR-only mIPSCs at immature synapses}

Our finding of mixed GABA ${ }_{\mathrm{A}} \mathrm{R}-\mathrm{GlyR}$ mIPSCs that are excluded with maturation in both laminas I and II in favor of GlyR-only or $\mathrm{GABA}_{\mathrm{A}} \mathrm{R}$-only mIPSCs raises the question of whether this specialization reflects a reorganization of presynaptic release or of postsynaptic receptor expression. To address this question, we used the benzodiazepine diazepam (DZP) $(1 \mu \mathrm{M})$ to increase the affinity of $\mathrm{GABA}_{\mathrm{A}} \mathrm{Rs}$ in lamina I and II neurons to test for the possibility that GABA may be co-released with glycine but remain subliminal to postsynaptic GABA ${ }_{\mathrm{A}}$ Rs. DZP was perfused on immature neurons $(n=5)$ with synaptic events being initially categorized into GlyR-only, $\mathrm{GABA}_{\mathrm{A}} \mathrm{R}$-only, and mixed $\mathrm{GABA}_{\mathrm{A}} \mathrm{R}-\mathrm{GlyR}$ mIPSCs on the basis of their decay kinetics (as described above). At the end of each recording, the validity of these categories was confirmed using strychnine and bicuculline administration sequentially and after full recovery from each application. Figure 4 illustrates the effect of diazepam administration to each of these types of mIPSCs. As shown in Figure 4A, GlyR-only mIPSC kinetics was not affected by perfusion of DZP. In the five cells tested, the decay time constant remained stable (control, $9.8 \pm 1.4 \mathrm{msec}$; DZP, $10 \pm 1.7 \mathrm{msec}$ ), in addition to the $10-90 \%$ rise time (control, $0.5 \pm 0.3 \mathrm{msec}$; DZP, $0.7 \pm 0.3 \mathrm{msec}$; data not shown) and the peak amplitude (control, $69.6 \pm 37.6 \mathrm{pA}$;

$\mathrm{GABA}_{\mathrm{A}} \mathrm{R}-\mathrm{GlyR}(C$, right $)$ was not significantly affected by the perfusion of DZP. There was, however, a significant fourfold increase in the instantaneous frequency of mixed $\mathrm{GABA}_{\mathrm{A}} \mathrm{R}-\mathrm{GlyR}$ mIPSCs that grew from $0.36 \mathrm{~Hz}$ in control conditions to $1.11 \mathrm{~Hz}$ with the administration of DZP $(p<0.01 ; C$, center $)$. No similar change in instantaneous frequency was noted for $\mathrm{GABA}_{\mathrm{A}} \mathrm{R}$-only mIPSCs $(B$, center $)$. The adequacy of the categorization of GlyR-only, $\mathrm{GABA}_{\mathrm{A}} \mathrm{R}$-only, and mixed $\mathrm{GABA}_{\mathrm{A}} \mathrm{R}-$ GlyR mIPSCs on the basis of their decay kinetics was confirmed with the sequential use of strychnine and bicuculline at the end of the recording (data not shown); measurements were made under steady-state conditions. Parameters under the influence of diazepam are indicated by gray lines or hatched bars, where appropriate. Cum. Prob., Cumulative probability; Inst. Freq., instantaneous frequency; Amp., peak amplitude. * $p<0.05$. 
DZP, $55.4 \pm 23.2 \mathrm{pA}$ ). However, the interevent interval of fast-decaying mIPSCs was significantly prolonged, corresponding to a reduction in frequency from $0.24 \pm 0.16$ to $0.09 \pm 0.06 \mathrm{~Hz}$ for control and DZP, respectively $(p<0.05 ; n=5)$.

DZP also induced an increase in the decay time constant of $\mathrm{GABA}_{\mathrm{A}} \mathrm{R}$-only mIPSCs that grew from $30.2 \pm 7.0 \mathrm{msec}$ (control) to $58.7 \pm 14.2 \mathrm{msec}$ (DZP; $n=5$ ) (Fig. $4 B$ ). None of the other kinetic parameters were significantly affected. When assessing the effects of DZP on mixed GABA ${ }_{\mathrm{A}} \mathrm{R}-$ GlyR mIPSCs (Fig. $4 C$ ), we found that the fast decay component remained stable (11.2 \pm 3.3 vs $10.1 \pm 3.1 \mathrm{msec}$ ), whereas the slow component doubled from $31.1 \pm 4.8$ to $67.4 \pm 16.9 \mathrm{msec}(n=5)$. The relative contribution of the fast-decaying component (GlyR-mediated) to the peak amplitude of mixed $\mathrm{GABA}_{\mathrm{A}} \mathrm{R}-\mathrm{GlyR}$ mIPSCs was also observed not to change with DZP application (control, $\mathrm{A}_{\mathrm{GlyR}} / \mathrm{A}_{\text {Total }}=$ $58.5 \pm 9.6, n=36 ; \mathrm{DZP}, \mathrm{A}_{\mathrm{GlyR}} / \mathrm{A}_{\text {Total }}=57.3 \pm 5.6, n=7 ; p>$ $0.05)$. Together, these results reinforce our conclusion that dualcomponent mIPSCs correspond to mixed $\mathrm{GABA}_{\mathrm{A}} \mathrm{R}-\mathrm{GlyR}$ mediated mIPSCs with the slow component being attributed to $\mathrm{GABA}_{\mathrm{A}} \mathrm{R}$ activation. More importantly, the frequency of mixed mIPSCs was significantly higher after DZP perfusion with values of $0.20 \pm 0.1$ and $0.31 \pm 0.13 \mathrm{~Hz}$ in control and DZP, respectively $(p<0.01 ; n=5)$. The total frequency of events was not significantly different between the control and DZP conditions $(0.21 \pm$ 0.06 vs $0.19 \pm 0.06 \mathrm{~Hz} ; p>0.05)$. Consistent with this, the reduction in GlyR-only $\mathrm{mIPSC}$ frequency was similar to the increase in mixed $\mathrm{GABA}_{\mathrm{A}} \mathrm{R}-\mathrm{GlyR}$ mIPSC frequency (for greater power of the test, comparison was made for each cell; the mean difference was $0.036 \pm 0.056 \mathrm{~Hz}$, not significantly different from zero; $p>0.05)$. We can thus conclude that the increase in mixed $\mathrm{GABA}_{\mathrm{A}} \mathrm{R}-\mathrm{GlyR}$ mIPSC frequency results directly from the DZP-induced conversion of GlyR-only mIPSCs into mixed $\mathrm{GABA}_{\mathrm{A}} \mathrm{R}-$ GlyR mIPSCs.

\section{Comparable potentiation of $\mathrm{GABA}_{A} \mathrm{R}$-mediated mIPSCs in immature versus adult neurons by diazepam}

To test for changes in $\mathrm{GABA}_{\mathrm{A}} \mathrm{R}$ subunit composition with maturation (Laurie et al., 1992), we applied DZP at the same concentration on isolated $\mathrm{GABA}_{\mathrm{A}} \mathrm{R}$-only events from both immature and adult superficial dorsal horn neurons. Perfusion of diazepam $(1 \mu \mathrm{M})$ induced a comparable approximately twofold increase in the decay time constant of pharmacologically isolated $\mathrm{GABA}_{\mathrm{A}} \mathrm{R}$ mediated mIPSCs in both immature (control, $30.2 \pm 7.0 \mathrm{msec}$, vs diazepam, $58.7 \pm 14.2 \mathrm{msec} ; n=5$ ) and adult (control, $14.4 \pm 0.6$ msec, vs diazepam, $27.3 \pm 0.9 \mathrm{msec} ; n=6$ ) neurons. Figure 5 illustrates such a potentiation for isolated $\mathrm{GABA}_{\mathrm{A}} \mathrm{R}$-mediated mIPSCs in lamina II neurons. This finding indicates that the sensitivity of immature and adult $\mathrm{GABA}_{\mathrm{A}}$ Rs to diazepam was not significantly different.

\section{Age-dependence of mIPSC kinetics}

Although no change was observed for the benzodiazepine sensitivity of $\mathrm{GABA}_{\mathrm{A}}$ Rs with maturation, we found significant alterations in the decay time course of both pharmacologically isolated $\mathrm{GABA}_{\mathrm{A}}$ R-only and GlyR-only mIPSCs with maturation. Specifically, GABA $\mathrm{A}_{\mathrm{A}} \mathrm{R}$-only mIPSCs showed a linear threefold quickening of decay time between P8 and P23 (from $35.0 \pm 3.0$ to $10.0 \pm 0.6 \mathrm{msec}$ ) (Fig. 6B). In contrast, GlyR-only mIPSCs exhibited a smaller decrease in decay time with maturation (from $9.8 \pm 1.0$ to $5.8 \pm 0.3 \mathrm{msec}$ ) (Fig. $6 B$ ). Interestingly, this decrease in the decay time constant for GlyR-only mIPSCs appeared to
A

B
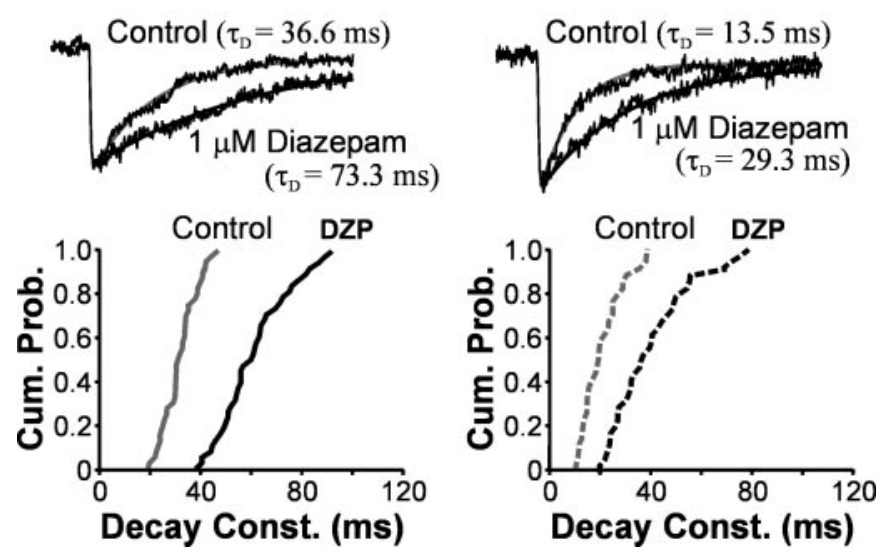

Figure 5. The diazepam-induced prolongation of the decay phase of $\mathrm{GABA}_{\mathrm{A}} \mathrm{R}$-only mIPSCs was similar among neurons from immature (P8P23) and adult superficial dorsal horn. $A$, This cumulative probability plot illustrates the $\sim 100 \%$ potentiation of isolated GABA $_{\mathrm{A}} \mathrm{R}$-only mIPSCs recorded from a P13 lamina II neuron after application of DZP (control, $36.6 \mathrm{msec}$, solid gray line, vs DZP, $73.3 \mathrm{msec}$, solid black line). B, A similar potentiation $(117 \%)$ was observed in adult neurons with an increase in the decay time constant from $13.5 \mathrm{msec}$ (dashed gray line) to $29.3 \mathrm{msec}$ (dashed black line). Both cumulative probability plots show a similar rightward shift in decay distribution, suggesting that the whole population of $\mathrm{GABA}_{\mathrm{A}} \mathrm{R}$ mIPSCs was affected by DZP. The insets in $A$ and $B$ show averaged representative traces illustrating the potentiation by DZP. Each trace was appropriately fitted by a monoexponential function. Cum. Prob., Cumulative probability; Decay Const., decay time constant.

coincide more closely with the period in which the proportion of mixed mIPSCs declined, from P15 to P23. There was also a decrease in the $10-90 \%$ rise time of both GABA $_{\mathrm{A}} \mathrm{R}$-only and GlyR-only mIPSCs (Fig. 6A). The fact that the ratio of $\mathrm{GABA}_{\mathrm{A}} \mathrm{R}$-only/GlyR-only rise time remained constant at $\sim 1.3$ (see also Fig. 8), however, suggests that the shortening of both rise times may be caused by a similar mechanism, such as a change in the degree of electrotonic filtering with maturation. Alternatively, the ratio of $\mathrm{GABA}_{\mathrm{A}} \mathrm{R}$-only to GlyR-only decay time constant was not constant, falling from $\sim 4.5$ at $\mathrm{P} 8$ to $\sim 2$ at P23 (Fig. 6C), indicating that changes in electrotonic filtering are not sufficient to explain this differential change in decay kinetics.

In addition to changes in kinetics, mIPSCs were significantly larger in adult animals than in immature animals. In lamina I, GlyR-mediated mIPSCs were $24.4 \pm 4.8 \mathrm{pA}(n=10)$ in immature animals versus $74.4 \pm 10.2 \mathrm{pA}(n=12)$ in adults. A similar increase in mIPSC amplitude was observed in lamina II for both isolated GlyR-mediated $(47.1 \pm 3.5 \mathrm{pA}, n=39$, vs $76.8 \pm 5.8 \mathrm{pA}$, $n=32)$ and $\mathrm{GABA}_{\mathrm{A}} \mathrm{R}$-mediated $(44.7 \pm 3.3 \mathrm{pA}, n=39$, vs $56.1 \pm 6.3 \mathrm{pA}, n=22)$ mIPSCs .

\section{Change in net inhibitory charge carried by mIPSCs}

As a direct consequence of the reduced duration of $G_{A B A} R$ only mIPSCs, in addition to the loss of mixed mIPSCs in the adult superficial dorsal horn, the net inhibitory charge carried by individual mIPSCs recorded from lamina I neurons was dramatically decreased. Figure 7 illustrates that in P8 lamina I neurons, which principally develop GlyR-dominant synaptic junctions, individual mIPSCs carried a mean net inhibitory charge of $668.7 \pm$ $72.1 \mathrm{fC}(n=7)$. This net charge is roughly $50 \%$ greater than that carried by mIPSCs in P20 lamina I neurons (445.0 $\pm 26.9 \mathrm{fC} ; n=$ $3 ; p<0.05)$, despite comparable mIPSC amplitudes (P8, $23.5 \pm$ 
A
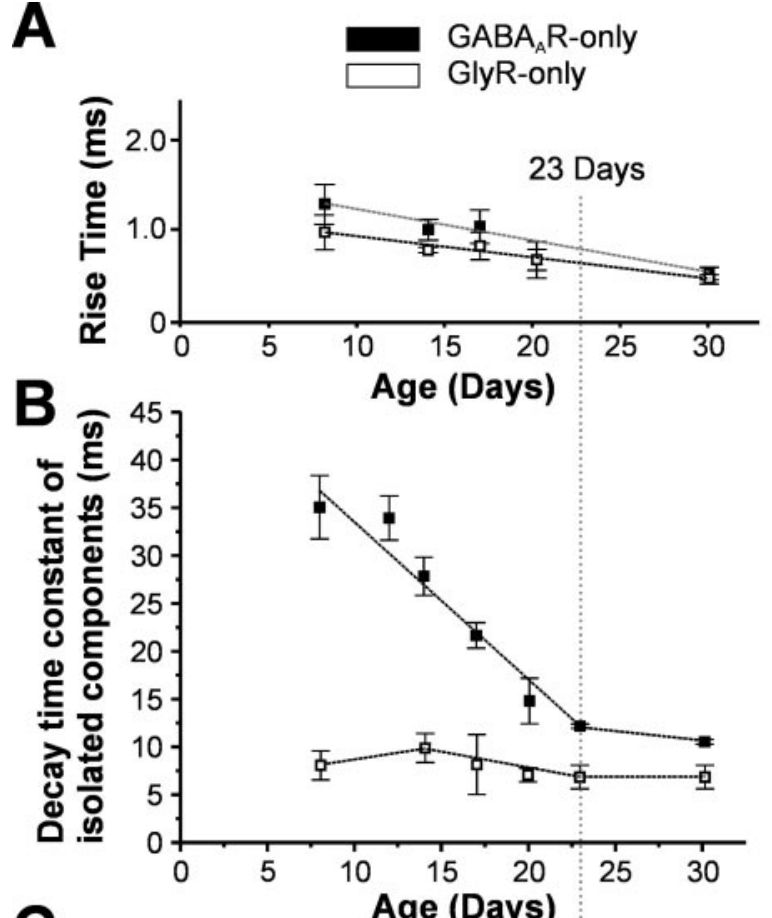

C

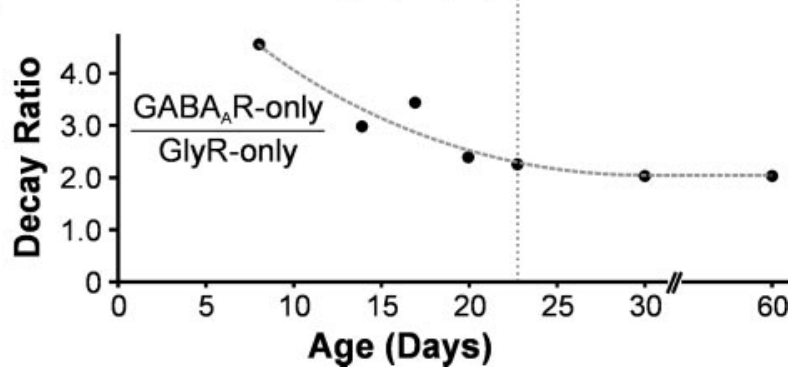

Figure 6. The kinetics of both $\mathrm{GABA}_{\mathrm{A}} \mathrm{R}$-only and GlyR-only mIPSCs changed with maturation. $A$, Both GABA $\mathrm{R}$-only and GlyR-only mIPSCs displayed a decrease in $10-90 \%$ rise time over the course of maturation. This decrease in rise time was, however, similar among $\mathrm{GABA}_{\mathrm{A}} \mathrm{R}$-only and GlyR-only mIPSCs, and thus the ratio of rise times between these two types of mIPSCs remained constant throughout development (all data points, $2 \leq n \leq 4)$. $B$, GABA A $_{\mathrm{A}}$-only mIPSCs displayed a fourfold reduction in decay time constant (from $35.0 \pm 3.0$ to $10.0 \pm 0.6 \mathrm{msec}$ ) between P8 and P23 (open square). After showing a slight increase, GlyR-only mIPSC decay time decreased twofold (from $9.8 \pm 1.0$ to $5.8 \pm$ $0.3 \mathrm{msec}$ ) between P14 and P23 (closed square); all data points, $2 \leq n \leq$ 4. $C$, The ratio of the $\mathrm{GABA}_{\mathrm{A}} \mathrm{R}$-only to GlyR-only decay time constant thus decreased from 4.5 at P8 to $\sim 2$ at P23 and onward. Note that P23 (dotted line) represents the time point by which mixed $\mathrm{GABA}_{\mathrm{A}} \mathrm{R}-\mathrm{GlyR}$ mIPSCs virtually disappear in all neurons from laminas I and II.

$1.8 \mathrm{pA}, n=7$, vs P20, $25.6 \pm 1.2 \mathrm{pA}, n=3$ ). Even in adult lamina I neurons, which displayed mIPSCs with significantly greater amplitude $(86.5 \pm 2.5 \mathrm{pA} ; n=3)$, the net inhibitory charge carried by mIPSCs $(509.7 \pm 69.2 \mathrm{fC} ; n=3)$ remained less than that of P8 lamina I neurons.

Analysis of the development of net quantal inhibition in lamina II neurons was difficult because age-dependent specialization results in a mixed population in this area (i.e., adult cells display varying proportions of GlyR-only vs $\mathrm{GABA}_{\mathrm{A}} \mathrm{R}$-only mIPSCs). It is interesting to note, however, that for cells with a greater proportion of $\mathrm{GABA}_{\mathrm{A}} \mathrm{R}$ mIPSCs, the reduction in net quantal inhibition with maturation is tempered because of the more prolonged decay kinetics of these synaptic currents in adult ani-
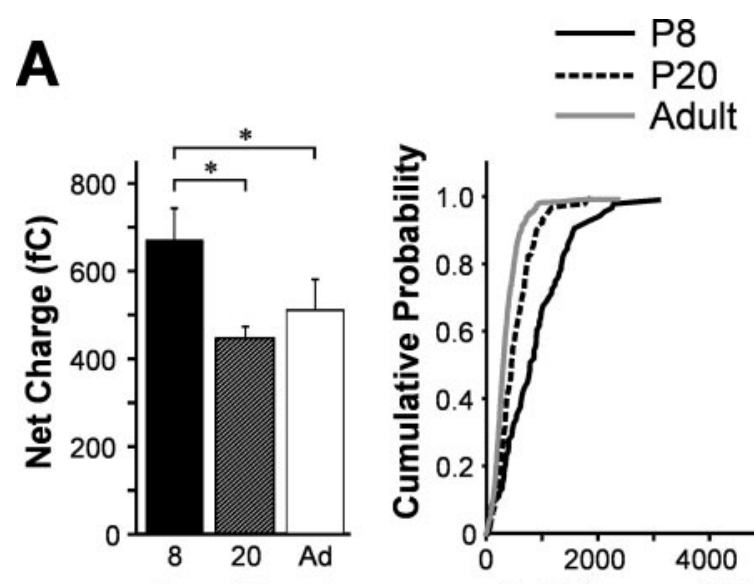

Age (Days)
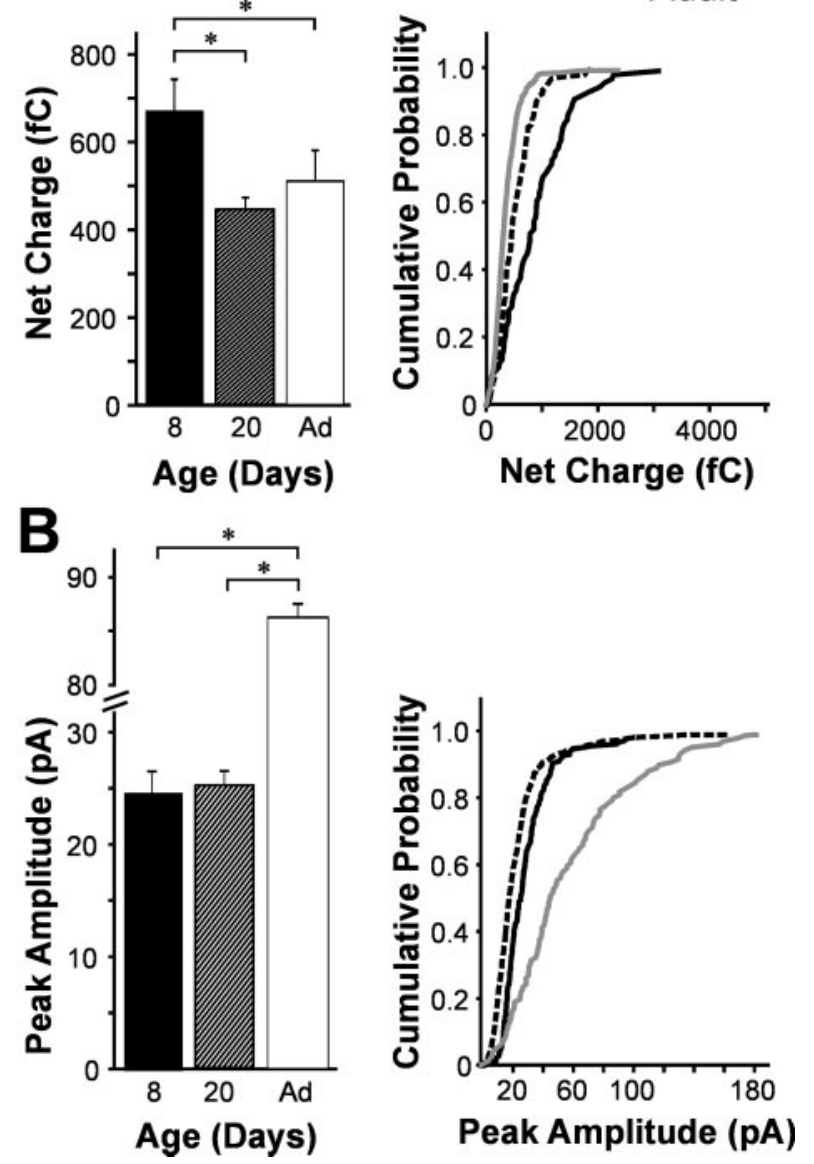

Figure 7. The loss of mixed GABA ${ }_{\mathrm{A}} \mathrm{R}-\mathrm{GlyR}$ mIPSCs, in addition to the decrease in mIPSC duration with development, resulted in a reduction in the net inhibitory charge carried by individual mIPSCs. A, Left, Lamina I neurons of age P8 (solid black bar) displayed mIPSCs that carried significantly greater net inhibitory charge $(668.7 \pm 72.1 \mathrm{fC} ; n=7)$ than either P20 lamina I neurons (hatched bar; $445.0 \pm 26.9 \mathrm{fC} ; n=3 ; p<0.05$ ) or adult lamina I neurons (solid white bar; $509.7 \pm 69.2 \mathrm{fC} ; n=3 ; p<$ $0.05)$. A representative cumulative probability distribution of mIPSC net inhibitory charge is shown on the right for three neurons, each taken from one of the age groups. B, Left, The greater net charge of mIPSCs displayed by P8 neurons when compared with P20 and adult neurons occurred despite similar peak amplitudes of mIPSCs among P8 and P20 lamina I neurons $(\mathrm{P} 8,23.5 \pm 1.8 \mathrm{pA}, n=7$, vs P20, $25.6 \pm 1.2 \mathrm{pA}, n=$ $3 ; p>0.05)$ and a significantly greater peak amplitude of mIPSCs in adult lamina I $(86.5 \pm 2.5 \mathrm{pA} ; n=3 ; p<0.01)$. Right, A representative cumulative probability distribution of mIPSC peak amplitudes is shown for three neurons, each taken from one of the age groups. ${ }^{*} p<0.05$.

mals (Fig. 6). Thus, these cells appear to develop a smaller deficit of inhibition with maturation than neurons in which quantal inhibition is predominantly mediated by GlyRs.

These observations emphasize the impact of the change in mIPSC kinetics and composition on the net inhibition of the cell during the maturation process and further demonstrate the distinction in development among lamina I and II neurons.

\section{Comparison of mIPSC rise times}

In our previous study of adult lamina I neurons, we found that the $\mathrm{GABA}_{\mathrm{A}} \mathrm{R}$-component that was unveiled with the use of a benzodiazepine had a much slower $(>10 \times)$ rise time than its GlyR counterpart. Because the two components were part of the same 


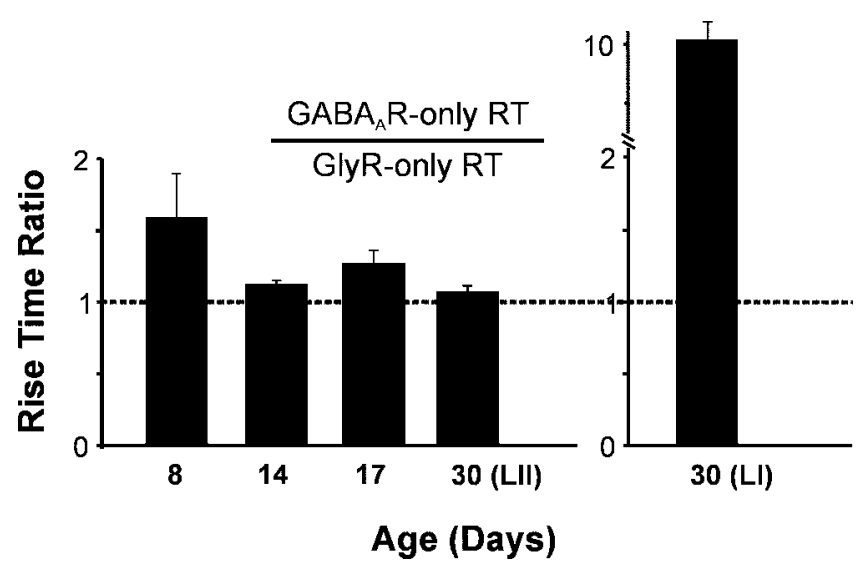

Figure 8. Difference in the ratio of $\mathrm{GABA}_{\mathrm{A}} \mathrm{R}$-only to GlyR-only mI PSC rise time in immature and adult lamina I-II neurons. In immature neurons (P8-P23), the ratio of $\mathrm{GABA}_{\mathrm{A}} \mathrm{R}$-only mIPSCs $10-90 \%$ rise time to that of GlyR-only mIPSCs was relatively stable, with a mean ratio of 1.3. This ratio was also not significantly different in adult lamina II neurons. In contrast, GABA ${ }_{\mathrm{A}}$ R-only mIPSCs revealed by $1 \mu \mathrm{M}$ flunitrazepam in adult lamina I exhibited a rise time $(4.1 \pm 0.9 \mathrm{msec})$ that was $>10 \times$ that of GlyR-only mIPSCs $(0.4 \pm 0.04 \mathrm{msec})$.

mIPSC, and thus originated from co-release from the same presynaptic terminal, we had hypothesized that this may indicate that $\mathrm{GABA}_{\mathrm{A}}$ Rs may be located perisynaptically at lamina I inhibitory synapses. We thus decided to contrast this result with values of rise time at different stages of development.

Interestingly, we found that individual $10-90 \%$ rise times from the GlyR-only and $\mathrm{GABA}_{\mathrm{A}} \mathrm{R}$-only mIPSCs were similar in immature neurons, displaying a constant mean ratio of $\sim 1.3$ $\left(\mathrm{GABA}_{\mathrm{A}} \mathrm{R}\right.$ rise/GlyR rise) in both laminas $(n=11)$ (Fig. 8). In the adult, despite the disappearance of mixed mIPSCs, the rise time ratio between $\mathrm{GABA}_{\mathrm{A}}$-only and GlyR-only mIPSCs also remained stable in lamina II. This result was in sharp contrast with that from adult lamina I neurons that normally only display GlyR-mediated mIPSCs. In the latter case, the benzodiazepinerevealed $\mathrm{GABA}_{\mathrm{A}} \mathrm{R}$ component of mIPSCs had a much slower rise time $(>10 \times)$ than that of its GlyR counterpart or that of $\mathrm{GABA}_{\mathrm{A}} \mathrm{R}$ events recorded from lamina II neurons (Fig. 8) (Chéry and De Koninck, 1999b).

\section{DISCUSSION}

In this study we show that, in contrast to what is found in the adult, immature lamina I-II inhibitory synapses exhibit individual miniature IPSCs possessing both a GlyR- and a GABA $\mathrm{G}_{\mathrm{A}}$ mediated component in normal conditions. More importantly, although our results confirm previous evidence of copackaging and thus co-release of GABA and glycine from the same terminals in the spinal cord (Jonas et al., 1998; Chéry and De Koninck, 1999b; O'Brien and Berger, 1999), they also show that despite continued co-release of these transmitters throughout development, codetection ceases at lamina I-II adult synapses. This indicates an age-dependent postsynaptic tuning of inhibitory synapses in this area. Furthermore, we demonstrate that this pattern of development differs between lamina I, predominantly an output layer, and the more propriospinal lamina II, suggesting that synaptic tuning may be dictated by functional requirements.

\section{Maintenance of co-release, loss of codetection}

The observation of dual-component mIPSCs throughout maturation together with the fact that benzodiazepines can continually unmask mixed quantal events (Chéry and De Koninck, 1999b, and the present study) argues for the continuous copackaging and co-release of GABA and glycine at all ages. These mixed mIPSCs also indicate the coactivation of kinetically distinct junctional receptor-channel complexes and, because co-release appears to persist, the switch we observe is likely reflecting a postsynaptic change in transmitter detection at synaptic junctions. Although we cannot completely rule out a presynaptic reorganization to explain these developmentally mediated changes, several lines of evidence argue against this possibility. First, immunocytochemical evidence indicates that GABA-glycine colocalization persists uninterrupted in adulthood (Todd et al., 1996). Second, a decrease in the relative vesicular concentration of GABA is unlikely, given that the affinity of VIAAT for GABA is three times greater than that for glycine (Bedet et al., 2000). Although these arguments do not allow direct estimation of vesicular concentration, the fact that the amplitude of $\mathrm{GABA}_{\mathrm{A}} \mathrm{R}$-only mIPSCs and of the $\mathrm{GABA}_{\mathrm{A}} \mathrm{R}$ component of mixed mIPSCs was not increased by diazepam (although they were prolonged) suggests that the amount of GABA released during these quantal events was saturating (De Koninck and Mody, 1994), arguing against low vesicular content.

The observation that all three combinations, mixed $\mathrm{GABA}_{\mathrm{A}} \mathrm{R}-$ GlyR mIPSCs, GlyR-only mIPSCs, and GABA ${ }_{\mathrm{A}}$ R-only mIPSCs, are present in the same cell and the fact that benzodiazepine can convert many GlyR-only mIPSCs into mixed $\mathrm{GABA}_{\mathrm{A}} \mathrm{R}-\mathrm{GlyR}$ mIPSCs suggests the existence of a heterogeneous junctional distribution of $\mathrm{GABA}_{\mathrm{A}}$ Rs and GlyRs in spinal laminas I and II. A differential distribution of receptor subtypes or subunits at distinct junctions within the same cell has been reported previously for other receptors (Dodt et al., 1998; Toth and McBain, 1998). Furthermore, a developmental shift from GABAergic to glycinergic transmission has been observed in some systems (Kotak et al., 1998). The alteration described in the latter study also appeared to occur at the postsynaptic level, but at earlier stages (P3-P12) than what we observed in spinal laminas I-II (P14-P23).

The pattern of distribution of mIPSC type among lamina I-II neurons was also different. In lamina I, for example, in which virtually all cells will display only GlyR-mediated mIPSCs in the adult, as little as $29 \%$ of GlyR-only events were present at P8. The reason for this is unknown, but it is interesting to note that a similar pattern of development in the rat ventral horn has been reported (Colin et al., 1998). In that study, it was shown that, at birth, the points of gephyrin-immunoreactivity (IR) outnumber GlyR-IR significantly. GlyR-IR only matched gephyrin-IR by P10, with proliferation of these GlyR-gephyrin microdomains occurring gradually with development. In light of reports linking the $\mathrm{GABA}_{\mathrm{A}} \mathrm{R}$ to gephyrin (Bohlhalter et al., 1994; Todd et al., 1996; Sassoe-Pognetto et al., 2000), this same group suggested that early unmatched gephyrin sites may be associated with the expression of a perinatal $\mathrm{GABA}_{\mathrm{A}} \mathrm{R}$. Indeed, it does now seem that gephyrin is required for the postsynaptic localization of $\mathrm{GABA}_{\mathrm{A}} \mathrm{Rs}$ (for review, see Kneussel et al., 1999), perhaps via cytoskeletal interactions (Wang et al., 1999). Transient expression of $\mathrm{GABA}_{\mathrm{A}} \mathrm{Rs}$ at early postnatal stages has also been reported in rat retina (Koulen, 1999) and other regions of the brain (Laurie et al., 1992; Poulter et al., 1992). These findings could explain why neurons that appear to express only junctional GlyRs in the adult stage display a significant proportion of mIPSCs with a GABA ${ }_{\mathrm{A}} \mathrm{R}$ component at developmental stages. 


\section{Mechanisms of synaptic switch}

The loss of codetection of co-released GABA and glycine likely involves a change in the affinity of the receptors, their expression, or subsynaptic distribution. It is reasonable to hypothesize that these changes are linked to altered subunit expression and/or intracellular regulatory mechanisms. Many reports, for example, suggest that differences in subunit composition affect subcellular localization (Nusser et al., 1998; Brickley et al., 1999; Crestani et al., 1999; Hutcheon et al., 2000; Sassoe-Pognetto et al., 2000). Similarly, phosphorylation mechanisms have been reported to interfere with translocation of $\mathrm{GABA}_{\mathrm{A}} \mathrm{Rs}$ to postsynaptic domains (Wan et al., 1997b).

A switch in receptor subunit expression has been proposed to underlie changes in kinetics of GlyRs during development (Takahashi et al., 1992). Although we also observed a shortening of GlyR-mediated mIPSCs, the change reported by Takahashi et al. (1992) appears to be largely completed by the beginning of the second postnatal week, which does not fit with the time frame reported here (between P15 and P23). Similarly, we observed a shortening of the decay kinetics of $\mathrm{GABA}_{\mathrm{A}} \mathrm{R}$ mIPSCs, consistent with that previously reported in other areas (Gao and ZiskindConhaim, 1995; Tia et al., 1996; Hollrigel and Soltesz, 1997; Dunning et al., 1999). The possibility that this change may be related to altered subunit expression during maturation in the spinal cord (Poulter et al., 1992) must be considered, given the recent data associating the shortening of GABA $\mathrm{A}_{\mathrm{A}}$-mIPSC decay with an increase in $\alpha 1$ subunit expression in cerebellar neurons (Vicini et al., 2001). This subunit, however, appears to be absent in adult laminas I-II (Persohn et al., 1991; Bohlhalter et al., 1996), suggesting that it may not underlie kinetic changes observed in the spinal cord. Our results also indicate that any switch should not involve an altered subunit composition affecting diazepam sensitivity.

\section{Functional significance}

The significance of the transient occurrence of mixed $\mathrm{GABA}_{\mathrm{A}} \mathrm{R}-$ GlyR quantal events during the maturation process may lie within the development of synapses themselves. Recently, it has been shown that the postsynaptic clustering of glycine receptors is activity-dependent (Kirsch and Betz, 1998). More specifically, the release of glycine from presynaptic terminals and subsequent depolarization elicited by perinatal GlyRs $(<\mathrm{P} 7)$ (Reichling et al., 1994; Wang et al., 1994) appears to be required for the aggregation of gephyrin that clusters GlyRs. The presence of $\mathrm{GABA}_{\mathrm{A}} \mathrm{Rs}$, which are also depolarizing before $\sim \mathrm{P} 7$ (Obrietan and van den Pol, 1995; Serafini et al., 1995; Boehm et al., 1997) may augment this activity-dependent formation of GlyR synapses.

Furthermore, transient $\mathrm{GABA}_{\mathrm{A}} \mathrm{R}$ expression at developing glycinergic synaptic junctions might also play a more ancillary role. GABAergic signaling has been shown to be important in early arborization (Spoerri, 1988; Behar et al., 1996) and is known to display a synergistic relationship with developing glutamatergic transmitter systems (Leinekugel et al., 1999).

Alternatively, coexpression of $\mathrm{GABA}_{\mathrm{A}} \mathrm{Rs}$ and GlyRs at the same junctions may allow for optimal activity-dependent formation of $\mathrm{GABA}_{\mathrm{A}} \mathrm{R}$ synapses, because it is now clear that gephyrin plays some role in the clustering of $\mathrm{GABA}_{\mathrm{A}} \mathrm{Rs}$ (for review, see Kneussel and Betz, 2000). Poulter et al. (1997) reported that synapse formation itself may regulate the selective trafficking of $\mathrm{GABA}_{\mathrm{A}} \mathrm{R}$ subunit mRNA during synaptogenesis. This finding is of particular importance in the interpretation of our results. That is, perhaps in lamina $\mathrm{I} \mathrm{GABA}_{\mathrm{A}} \mathrm{Rs}$ are first required to be expressed at synaptic junctions in immature dorsal horn to initiate activity-dependent migration to extrajunctional sites in the adult. The possibility that this migration is mediated by a subunit switch is supported by a second study from the same group that suggests that perinatal $\mathrm{GABA}_{\mathrm{A}}$ receptor activity may regulate the developmental switchover of $\mathrm{GABA}_{\mathrm{A}}$ receptor subunit mRNA expression (Poulter and Brown, 1999).

The possibility that the transient occurrence of junctional $\mathrm{GABA}_{\mathrm{A}} \mathrm{R}$ and GlyR coactivation represents a protective mechanism must also be considered. It has been reported, for example, that supraspinal descending inhibitory pathways do not become fully functional until the third postnatal week (Van Praag et al., 1993; Falcon et al., 1996). A greater net inhibitory charge carried by quantal mIPSCs could therefore allow the intrinsic circuitry to accomplish sufficient inhibition of neuronal excitability in the absence of extrinsic inhibitory input. Alternatively, a greater net charge could also serve as a protective mechanism during the development of glutamatergic transmission, because it has been reported that $\mathrm{GABA}_{\mathrm{A}} \mathrm{R}$ synapses precede glutamatergic synapses (Tyzio et al., 1999).

Previous evidence suggests that $\mathrm{GABA}_{\mathrm{A}}$ synapses can be made silent in a rapidly reversible manner (Poisbeau et al., 1997). Knowing that the functional properties of synaptic $\mathrm{GABA}_{\mathrm{A}} \mathrm{Rs}$ are regulated by intracellular mechanisms (Wan et al., 1997a,b; Poisbeau et al., 1999), it is possible that the loss of a GABAergic contribution to quantal inhibitory events with maturation may represent a type of contingency organization. For instance, in normal adult lamina I, GABA $\mathrm{A}_{\mathrm{A}}$ do not appear to contribute to basal inhibition, yet they may be brought into play in conditions such as the hyperexcitability characteristic of chronic pain (Chéry and De Koninck, 1999a).

\section{REFERENCES}

Bedet C, Isambert MF, Henry JP, Gasnier B (2000) Constitutive phosphorylation of the vesicular inhibitory amino acid transporter in rat central nervous system. J Neurochem 75:1654-1663.

Behar TN, Li YX, Tran HT, Ma W, Dunlap V, Scott C, Barker JL (1996) GABA stimulates chemotaxis and chemokinesis of embryonic cortical neurons via calcium-dependent mechanisms. J Neurosci 16:1808-1818.

Boehm S, Harvey RJ, von Holst A, Rohrer H, Betz H (1997) Glycine receptors in cultured chick sympathetic neurons are excitatory and trigger neurotransmitter release. J Physiol (Lond) 504:683-694.

Bohlhalter S, Mohler H, Fritschy JM (1994) Inhibitory neurotransmission in rat spinal cord: co-localization of glycine- and GABAAreceptors at GABAergic synaptic contacts demonstrated by triple immunofluorescence staining. Brain Res 642:59-69.

Bohlhalter S, Weinmann O, Mohler H, Fritschy JM (1996) Laminar compartmentalization of GABAA-receptor subtypes in the spinal cord: an immunohistochemical study. J Neurosci 16:283-297.

Brickley SG, Cull-Candy SG, Farrant M (1999) Single-channel properties of synaptic and extrasynaptic GABAA receptors suggest differential targeting of receptor subtypes. J Neurosci 19:2960-2973.

Chaudhry FA, Reimer RJ, Bellocchio EE, Danbolt NC, Osen KK, Edwards RH, Storm-Mathisen J (1998) The vesicular GABA transporter, VGAT, localizes to synaptic vesicles in sets of glycinergic as well as GABAergic neurons. J Neurosci 18:9733-9750.

Chéry N, De Koninck Y (1999a) Disinhibition underlies hyperexcitability of spinal cord lamina I neurons in rats with experimental neuropathy. Soc Neurosci Abstr 25:1672.

Chéry N, De Koninck Y (1999b) Junctional versus extrajunctional glycine and GABA(A) receptor-mediated IPSCs in identified lamina I neurons of the adult rat spinal cord. J Neurosci 19:7342-7355.

Chéry N, Yu XH, De Koninck Y (2000) Visualization of lamina I of the dorsal horn in live adult rat spinal cord slices. J Neurosci Methods 96:133-142.

Colin I, Rostaing P, Augustin A, Triller A (1998) Localization of components of glycinergic synapses during rat spinal cord development. J Comp Neurol 398:359-372.

Coull JAM, Keller AF, Chéry N, De Koninck Y, Poisbeau P (2000) Shift in subsynaptic receptor distribution underlies maturation of GABA/ 
glycine cosynapse in the superficial spinal dorsal horn. Soc Neurosci Abstr 26:1393.

Crestani F, Lorez M, Baer K, Essrich C, Benke D, Laurent JP, Belzung C, Fritschy JM, Luscher B, Mohler H (1999) Decreased GABAAreceptor clustering results in enhanced anxiety and a bias for threat cues. Nat Neurosci 2:833-839.

De Koninck Y, Mody I (1994) Noise analysis of miniature IPSCs in adult rat brain slices: properties and modulation of synaptic GABAA receptor channels. J Neurophysiol 71:1318-1335.

De Koninck Y, Mody I (1996) The effects of raising intracellular calcium on synaptic GABAA receptor-channels. Neuropharmacology 35:1365-1374.

Dodt HU, Frick A, Kampe K, Zieglgansberger W (1998) NMDA and AMPA receptors on neocortical neurons are differentially distributed. Eur J Neurosci 10:3351-3357.

Dumoulin A, Rostaing P, Bedet C, Levi S, Isambert MF, Henry JP, Triller A, Gasnier B (1999) Presence of the vesicular inhibitory amino acid transporter in GABAergic and glycinergic synaptic terminal boutons. J Cell Sci 112:811-823.

Dunning DD, Hoover CL, Soltesz I, Smith MA, O'Dowd DK (1999) GABA(A) receptor-mediated miniature postsynaptic currents and alpha-subunit expression in developing cortical neurons. J Neurophysiol 82:3286-3297.

Falcon M, Guendellman D, Stolberg A, Frenk H, Urca G (1996) Development of thermal nociception in rats. Pain 67:203-208.

Gao BX, Ziskind-Conhaim L (1995) Development of glycine- and GABA-gated currents in rat spinal motoneurons. J Neurophysiol 74:113-121.

Gasnier B (2000) The loading of neurotransmitters into synaptic vesicles. Biochimie 82:327-337.

Hoffman AF, Lupica CR (2000) Mechanisms of cannabinoid inhibition of $\operatorname{GABA}(\mathrm{A})$ synaptic transmission in the hippocampus. J Neurosci 20:2470-2479.

Hollrigel GS, Soltesz I (1997) Slow kinetics of miniature IPSCs during early postnatal development in granule cells of the dentate gyrus. J Neurosci 17:5119-5128.

Hutcheon B, Morley P, Poulter MO (2000) Developmental change in GABAA receptor desensitization kinetics and its role in synapse function in rat cortical neurons. J Physiol (Lond) 522:3-17.

Jonas P, Bischofberger J, Sandkuhler J (1998) Corelease of two fast neurotransmitters at a central synapse. Science 281:419-424.

Kirsch J, Betz H (1998) Glycine-receptor activation is required for receptor clustering in spinal neurons. Nature 392:717-720.

Kneussel M, Betz H (2000) Receptors, gephyrin and gephyrinassociated proteins: novel insights into the assembly of inhibitory postsynaptic membrane specializations. J Physiol (Lond) 525:1-9.

Kneussel M, Brandstatter JH, Laube B, Stahl S, Muller U, Betz H (1999) Loss of postsynaptic GABA(A) receptor clustering in gephyrindeficient mice. J Neurosci 19:9289-9297.

Kotak VC, Korada S, Schwartz IR, Sanes DH (1998) A developmental shift from GABAergic to glycinergic transmission in the central auditory system. J Neurosci 18:4646-4655.

Koulen P (1999) Postnatal development of GABAA receptor beta1, beta $2 / 3$, and gamma 2 immunoreactivity in the rat retina. J Neurosci Res 57:185-194.

Laurie DJ, Wisden W, Seeburg PH (1992) The distribution of thirteen GABAA receptor subunit mRNAs in the rat brain. III. Embryonic and postnatal development. J Neurosci 12:4151-4172.

Leinekugel X, Khalilov I, McLean H, Caillard O, Gaiarsa JL, Ben-Ari Y, Khazipov R (1999) GABA is the principal fast-acting excitatory transmitter in the neonatal brain. Adv Neurol 79:189-201.

Mitchell K, Spike RC, Todd AJ (1993) An immunocytochemical study of glycine receptor and GABA in laminae I-III of rat spinal dorsal horn. J Neurosci 13:2371-2381.

Nusser Z, Sieghart W, Somogyi P (1998) Segregation of different GABAA receptors to synaptic and extrasynaptic membranes of cerebellar granule cells. J Neurosci 18:1693-1703.

O'Brien JA, Berger AJ (1999) Cotransmission of GABA and glycine to brain stem motoneurons. J Neurophysiol 82:1638-1641.

Obrietan K, van den Pol AN (1995) GABA neurotransmission in the hypothalamus: developmental reversal from $\mathrm{Ca} 2+$ elevating to depressing. J Neurosci 15:5065-5077.

Persohn E, Malherbe P, Richards JG (1991) In situ hybridization histochemistry reveals a diversity of $\mathrm{GABA}_{\mathrm{A}}$ receptor subunit mRNAs in neurons of the rat spinal cord and dorsal root ganglia. Neuroscience 42:497-507.

Poisbeau P, Williams SR, Mody I (1997) Silent GABAA synapses during flurazepam withdrawal are region-specific in the hippocampal formation. J Neurosci 17:3467-3475.

Poisbeau P, Cheney MC, Browning MD, Mody I (1999) Modulation of synaptic GABAA receptor function by $\mathrm{PKA}$ and $\mathrm{PKC}$ in adult hippocampal neurons. J Neurosci 19:674-683.

Poulter MO, Brown LA (1999) Transient expression of GABAA receptor subunit mRNAs in the cellular processes of cultured cortical neurons and glia. Brain Res Mol Brain Res 69:44-52.

Poulter MO, Barker JL, O’Carroll AM, Lolait SJ, Mahan LC (1992) Differential and transient expression of GABAA receptor alphasubunit mRNAs in the developing rat CNS. J Neurosci 12:2888-2900.

Poulter MO, Ohannesian L, Larmet Y, Feltz P (1997) Evidence that GABAA receptor subunit mRNA expression during development is regulated by GABAA receptor stimulation. J Neurochem 68:631-639.

Reichling DB, Kyrozis A, Wang J, MacDermott AB (1994) Mechanisms of GABA and glycine depolarization-induced calcium transients in rat dorsal horn neurons. J Physiol (Lond) 476:411-421.

Sassoe-Pognetto M, Panzanelli P, Sieghart W, Fritschy JM (2000) Colocalization of multiple GABA(A) receptor subtypes with gephyrin at postsynaptic sites. J Comp Neurol 420:481-498.

Sciancalepore M, Savic N, Gyori J, Cherubini E (1998) Facilitation of miniature GABAergic currents by ruthenium red in neonatal rat hippocampal neurons. J Neurophysiol 80:2316-2322.

Serafini R, Valeyev AY, Barker JL, Poulter MO (1995) Depolarizing GABA-activated $\mathrm{Cl}^{-}$channels in embryonic rat spinal and olfactory bulb cells. J Physiol (Lond) 488:371-386.

Sherman SE, Loomis CW (1996) Strychnine-sensitive modulation is selective for non-noxious somatosensory input in the spinal cord of the rat. Pain 66:321-330.

Sorkin LS, Puig S (1996) Neuronal model of tactile allodynia produced by spinal strychnine: effects of excitatory amino acid receptor antagonists and a mu-opiate receptor agonist. Pain 68:283-292.

Spoerri PE (1988) Neurotrophic effects of GABA in cultures of embryonic chick brain and retina. Synapse $2: 11-22$.

Takahashi T, Momiyama A, Hirai K, Hishinuma F, Akagi H (1992) Functional correlation of fetal and adult forms of glycine receptors with developmental changes in inhibitory synaptic receptor channels. Neuron 9:1155-1161.

Tia S, Wang JF, Kotchabhakdi N, Vicini S (1996) Developmental changes of inhibitory synaptic currents in cerebellar granule neurons: role of GABA(A) receptor alpha 6 subunit. J Neurosci 16:3630-3640.

Todd AJ, Sullivan AC (1990) Light microscope study of the coexistence of GABA-like and glycine-like immunoreactivities in the spinal cord of the rat. J Comp Neurol 296:496-505.

Todd AJ, Watt C, Spike RC, Sieghart W (1996) Colocalization of GABA, glycine, and their receptors at synapses in the rat spinal cord. J Neurosci 16:974-982.

Toth K, McBain CJ (1998) Afferent-specific innervation of two distinct AMPA receptor subtypes on single hippocampal interneurons. Nat Neurosci 1:572-578.

Trudeau LE, Fang Y, Haydon PG (1998) Modulation of an early step in the secretory machinery in hippocampal nerve terminals. Proc Natl Acad Sci USA 95:7163-7168.

Tyzio R, Represa A, Jorquera I, Ben-Ari Y, Gozlan H, Aniksztejn L (1999) The establishment of GABAergic and glutamatergic synapses on CA1 pyramidal neurons is sequential and correlates with the development of the apical dendrite. J Neurosci 19:10372-10382.

Van Praag H, Falcon M, Guendelman D, Frenk H (1993) The development of analgesic, pro- and anti-convulsant opiate effects in the rat Ann Ist Super Sanita 29:419-429.

Vicini S, Ferguson C, Prybylowski K, Kralic J, Morrow AL, Homanics GE (2001) GABAA receptor alpha1 subunit deletion prevents developmental changes of inhibitory synaptic currents in cerebellar neurons. J Neurosci 21:3009-3016.

Wan Q, Man HY, Braunton J, Wang W, Salter MW, Becker L, Wang YT (1997a) Modulation of GABAA receptor function by tyrosine phosphorylation of beta subunits. J Neurosci 17:5062-5069.

Wan Q, Xiong ZG, Man HY, Ackerley CA, Braunton J, Lu W Y, Becker LE, MacDonald JF, Wang YT (1997b) Recruitment of functional GABA(A) receptors to postsynaptic domains by insulin. Nature 388:686-690.

Wang H, Bedford FK, Brandon NJ, Moss SJ, Olsen RW (1999) $\mathrm{GABA}(\mathrm{A})$-receptor-associated protein links $\mathrm{GABA}(\mathrm{A})$ receptors and the cytoskeleton. Nature 397:69-72.

Wang J, Reichling DB, Kyrozis A, MacDermott AB (1994) Developmental loss of GABA- and glycine-induced depolarization and $\mathrm{Ca} 2+$ transients in embryonic rat dorsal horn neurons in culture. Eur J Neurosci 6:1275-1280.

Yaksh TL (1989) Behavioral and autonomic correlates of the tactile evoked allodynia produced by spinal glycine inhibition: effects of modulatory receptor systems and excitatory amino acid antagonists. Pain 37:111-123. 